\title{
HUBUNGAN GAYA HIDUP SEHAT DAN INTENSITAS SUARA DENGAN KEJADIAN HIPERTENSI DI WILAYAH KERJA PUSKESMAS II CILONGOK KABUPATEN BANYUMAS TAHUN 2016
}

\author{
Rina Yuliana $^{1)}$, Tri Cahyono ${ }^{2)}$, Teguh Widiyanto ${ }^{3)}$ \\ Jurusan Kesehatan Lingkungan, Politeknik Kesehatan Kemenkes Semarang, \\ Jl. Raya Baturaden KM 12 Purwokerto, Indonesia
}

\begin{abstract}
Abstrak
Salah satu faktor yang berhubungan dengan kejadian penyakit hipertensi adalah gaya hidup yang berisiko dan intensitas suara yang tidak memenuhi syarat kesehatan. Puskesmas II Cilongok merupakan puskesmas yang semakin mengalami peningkatan jumlah penderita hipertensi yaitu berjumlah 1.663 orang (2015). Penelitian ini bertujuan untuk mengetahui hubungan dan besarnya nilai risiko antara gaya hidup dan intensitas suara dengan kejadian hipertensi.Penelitian ini bersifat observasional dengan menggunakan casse control. Sampel sebanyak 50 orang terdiri dari 25 orang kelompok kasus kemudian diambil kelompok kontrol 25 orang dengan jenis kelamin yang sama dan umur tidak berbeda jauh dan tidak menderita hipertensi. Variabel yang diteliti meliputi gaya hidup dan intensitas suara. Analisa univariat dan bivariat menggunakan SPSS dengan CI $=95 \%$ dan $\alpha=0,05$ serta multivariat dengan menggunakan regresi logistik ganda.Hasil penelitian ini menunjukkan bahwa ada hubungan antara gaya hidup sehat dengan kejadian hipertensi $(p=0,002$ dan $O R=8,142)$,dan terdapat hubungan antara intensitas suara dengan kejadian hipertensi $(p=0,118$ dan $O R=0)$, dapat disimpulkan bahwa gaya hidup sehat beresiko 8,124 kali terhadap kejadian hipertensi. Berdasarkan hasil penelitian, penulis menyarankan untuk menekan tingkat penderita hipertensi dengan menjaga gaya hidup sehat melalui olahraga yang teratur, mengkonsumsi makanan sehat, tidak merokok, tidak meminum minuman beralkohol dan mengurangi minum kopi serta melakukan gaya hidup sehat yang lainnya.
\end{abstract}

Kata kunci: Hipertensi, Gaya Hidup Sehat, Intensitas Suara.

\begin{abstract}
One of the factors associated with the incidence of hypertension is a lifestyle disease risk and intensity of sounds that do not meet health requirements. Community Health Centre II Cilongok an increasingly health centers have increased the number of patients with hypertension that is numbered 1,663 people (2015). This study aims to determine the relationship and the value of risk between lifestyle and the sound intensity with hypertension.Observational research using casse control. A sample of 50 people, consisting of 25 groups of cases later taken control group of 25 people with the same sex and age did not vary much and did not suffer from hypertension. Variables examined included life style and intensity of the sound. Univariate and bivariate analysis using SPSS with $C I=95 \%$ and $\alpha=0.05$ and using multivariate logistic regression. The results of this study indicate that there is a relationship between a healthy lifestyle with hypertension ( $p=0.002$ and $O R=8.142)$, and there is a relationship between the intensity of sound with hypertension ( $p=0.118$ and $O R=0)$, it can be concluded that $a$ healthy lifestyle at risk 8.124 times the incidence of hypertension.Based on the findings, the authors suggest to reduce the level of hypertensive patients to maintain a healthy lifestyle through regular exercise, eating a healthy diet, not smoking, not drinking alcohol and drink less coffee and make other healthy lifestyle.
\end{abstract}

Keywords : Hypertension, Healthy Lifestyle, Sound Intensity.

\section{Pendahuluan}

Salah satu masalah yang dapat timbul akibat perkembangan jaman adalah gaya hidup sehat tidak sehat yang dapat memicu munculnya penyakit degeneratif, yang salah satunya adalah hipertensi. Menurut Joint National Committee on Detection, Evaluation and Treatment of High Blood Pressure (JNC) hipertensi ditandai dengan tekanan darah yang lebih tinggi dari 140/90 mmHg dan diklasifikasikan sesuai derajat keparahannya.

Hipertensi pada awalnya dikenal sebagai penyakit yang hanya menyerang lansia, namun sekarang menurut Gofir (2002) hipertensi dapat muncul pada usia antara 25 sampai 55 tahun (digolongkan dalam hipertensi essensial atau

1) Email : yulianna_rina@yahoo.com

2) Email : Tricahyono37@yahoo.co.id

3) Email : Widiyantoteguh@yahoo.co.id 
hipertensi primer). Kesadaran dan pengetahuan tentang penyakit hipertensi di Indonesia masih sangat rendah hal ini terbukti dengan kebiasaan masyarakat yang lebih memilih makanan siap saji yang umumnya rendah serat, tinggi lemak, tinggi gula, dan mengandung banyak garam. Gaya hidup sehat yang kurang sehat ini memicu munculnya penyakit hipertensi (Martuti, 2009). Seluruh penderita hipertensi, ternyata sekitar 95\% kasus tidak dapat ditentukan penyebabnya (Gofir, 2002).

Berdasarkan data Dinas Kesehatan Kabupaten Banyumas tahun 2011 kejadian hipertensi yaitu 45.187 kejadian terdiri dari 41.981 (92,9\%) hipertensi primer dan 3.206 (7,1\%) hipertensi sekunder. Sementara kejadian hipertensi di wilayah kerja Puskesmas II Cilongok dari tahun ke tahun pun mengalami peningkatan. Jumlah pasien baru hipertensi di wilayah kerja Puskesmas II Cilongok menunjukan kenaikan setiap tahunnya. Pada tahun 2013 tercatat terdapat 714 kasus hipertensi, sedangkan pada tahun 2014 kejadian hipertensi meningkat menjadi 943 kasus dan pada tahun 2015 terjadi lagi peningkatan kasus hipertensi menjadi 1.663 kasus. Peningkatan kasus hipertensi yang terjadi di wilayah kerja Puskesmas II Cilongok ini perlu mendapatkan perhatian yang serius dari petugas kesehatan.

Peningkatan tekanan darah dipengaruhi oleh beberapa faktor risiko antara lain: usia, jenis kelamin, riwayat keluarga, obesitas, diet dan gaya hidup sehat (Martuti, 2009). Bagi penderita tekanan darah tinggi, sangat penting sekali untuk 3 membuat perubahan gaya hidup sehat yang positif dengan pola makan yang baik dan aktivitas yang cukup (Sigarlaki, 2006).

Menurut Crea (2008) menyatakan bahwa pada umumnya penderita hipertensi adalah orang-

orang yang berusia 45 tahun ke atas namun pada saat ini tidak menutup kemungkinan diderita oleh orang berusia muda. Beberapa hal yang dapat memicu penyakit hipertensi adalah ketegangan, kekhawatiran, status sosial, intensitas suara, gangguan dan kegelisahan. Pengendalian pengaruh dan emosi negatif tersebut tergantung juga pada kepribadian masing-masing individu.

Tingginya kejadian hipertensi di tengahtengah masyarakat perlu dikaji secara mendalam dan diketahui faktor-faktor yang mempengaruhinya. Hal ini akan berkontribusi positif bagi keperawatan komunitas dalam menggali dan mengetahui fenomena perilaku masyarakat yang secara langsung berdampak pada meningkatnya kejadian hipertensi. Pentingnya kajian mengenai hipertensi ini maka penulis tertarik untuk melakukan penelitian tentang "Hubungan Gaya hidup sehat dan
Intensitas Suara dengan Kejadian Hipertensi di Wilayah Kerja Puskesmas II Cilongok Kabupaten Banyumas Tahun 2016”.

\section{Bahan dan Metode}

Penelitian ini menggunakan penelitian analitik kuantitatif dengan pendekatan case control. Penelitian ini menggambarkan tentang gaya hidup sehat dan besarnya intensitas suara yang ada di wilayah kerja Puskesmas II Cilongok. Subyek dalam penelitian ini adalah penduduk yang ada di wilayah kerja Puskesmas II Cilongok tahun 2016 yaitu jumlah penderita hipertensi, karakteristik penderita hipertensi dan kelompok kontrolnya (umur dan jenis kelamin), kondisi penderita hipertensi dan kelompok kontrolnya (gaya hidup sehat dan intensitas suara). Cara dalam penelitian ini adalah dengan cara menggunakan kuisioner dan dengan cara mengamati langsung pada obyek yang diteliti dengan melakukan pengukuran.

\section{Hasil dan Pembahasan Hasil}

Puskesmas II Cilongok merupakan salah satu bagian wilayah Kabupaten Banyumas, dengan luas wilayah kurang lebih $42 \mathrm{~km}^{2}$ atau 3,25\% luas Kabupaten Banyumas. Wilayah Puskesmas II Cilongok terbagai dalam 9 desa, sedangkan desa yang mempunyai wilayah paling luas adalah Panusupan dengan luas \pm $8,64 \mathrm{~km}^{2}$ yang paling sempit adalah desa Sudimara dengan luas $\pm 1,87 \mathrm{~km}^{2}$, Kecamatan Cilongok merupakan Kecamatan yang mempunyai wilayah paling luas di Kabupaten Banyumas yaitu sekitar $10.534 \mathrm{Ha}$.

Kategori umur yang paling tinggi terkena kasus adalah pada rentang umur 31-44 tahun yaitu terdapat 24 kasus, sedangkan yang terendah pada rentang umur 21-30 tahun yaitu terdapat 1 kasus.

Responden jenis kelamin yang tertinggi pada kelompok kasus hipertensi adalah responden perempuan dengan 22 responden atau $88 \%$, kemudian laki - laki sebanyak 3 responden atau $12 \%$ sedangkan pada kelompok kontrol diketahui responden jenis kelamin tertinggi adalah responden perempuan dengan 22 responden atau 88\% kemudian laki - laki sebanyak 3 responden atau $12 \%$.

Kondisi gaya hidup sehat responden yang berisiko pada kelompok kasus sebanyak 19 kasus atau sebesar 76\% sedangkan kelompok kontrol yang tidak berisiko sebanyak 18 atau sebesar 72\% dan jumlah kelompok kasus kontrol pada kondisi gaya hidup sehat yang berisiko adalah sebanyak 26 dengan persentase $52 \%$.

Kondisi intensitas suara responden yang melebihi NAB pada kelompok kasus sebanyak 4 
kasus atau sebesar 16\% sedangkan kelompok kontrol yang tidak melebihi NAB sebanyak 25 atau sebesar $100 \%$ dan jumlah kelompok kasus kontrol pada kondisi intensitas suara yang melebihi NAB adalah sebanyak 4 dengan persentase $8 \%$.

Hasil uji statistik didapatkan nilai $\mathrm{p}=$ 0,002 lebih kecil dari 0,05 yang berarti secara statistik ada hubungan yang bermakna antara gaya hidup dengan kejadian hipertensi . Hasil perhitungan yang didapatkan, yaitu nilai OR = 8,143 , berarti responden yang mempunyai gaya hidup berisiko mempunyai kemungkinan 8,143 kali lebih banyak terkena hipertensi dibandingkan dengan gaya hidup yang tidak berisiko.

Hasil uji statistik didapatkan nilai $\mathrm{p}=$ 0,118 lebih besar dari 0,05 yang berarti secara statistik tidak ada hubungan yang bermakna antara intensitas suara dengan kejadian hipertensi .

Uji regresi linear berganda antara gaya hidup sehat dan intensitas suara dengan kejadian hipertensi di wilayah kerja Puskesmas II Cilongok Kabupaten Banyumas. Tabel tersebut menjelaskan bahwa step 1 menunjukkan dua variabel dianalisis secara bersama - sama mana yang lebih berpengaruh terhadap terjadinya hipertensi. Step 2 menunjukkan bahwa variabel yang muncul hanya gaya hidup dan variabel intensitas telah hilang. Variabel intensitas hilang karena pada step 1 memiliki nilai Sig paling besar yaitu 0.999. Variabel yang paling berpengaruh terhadap kejadian hipertensi adalah variabel yang mempunyai nilai Sig $<0,05$ yaitu gaya hidup. Nilai OR dari gaya hidup diatas dapat terlihat pada kolom $\operatorname{Exp(B)}$ yaitu 8,143, karena 8,143 > 1 maka variabel gaya hidup merupakan faktor risiko. Artinya seseorang yang mempunyai gaya hidup berisiko justru cenderung terkena penyakit hipertensi.

\section{Pembahasan}

Banyaknya penderita pada golongan usia produktif, menurut peneliti disebabkan oleh beberapa hal yaitu sebagai berikut :

a. Usia produktif merupakan usia seseorang lebih banyak melakukan aktifitas . Selain itu apabila tidak didukung oleh gizi yang memadai, maka dapat menurunkan kekebalan tubuh sehingga mengakibatkan seseorang mudah terserang penyakit seperti hipertensi.

b. Lebih banyak aktifitas dan mobilitas yang tinggi akan memungkinkan terjadinya kontak dengan yang lain yang disadari maupun tidak disadari.

c. Usia produktif tersebut disadari atau tidak disadari seseorang akan berperilaku kurang sehat yang berisiko dapat menurunkan kekebalan tubuh seperti kebiasaan merokok.

Jumlah penderita hipertensi di Puskesmas II Cilongok Kecamatan Cilongok Kabupaten Banyumas Tahun 2016 persentase penderita dengan jenis kelamin perempuan (88\%) lebih banyak dari penderita berjenis kelamin laki - laki (12\%). Hal ini menunjukkan bahwa perempuan lebih beraktifitas, memiliki gizi yang kurang memadai dan juga perilaku yang kurang sehat. Peneliti menemukan bahwa wanita berisiko 30-40\% lebih tinggi terkena hipertensi dibandingkan pria. Ada perbedaan secara fisiologis dalam sistem kardiovaskular antara pria dan wanita, termasuk kadar hormon yang terlibat dalam sistem peredaran darah.

Gaya hidup masyarakat di wilayah kerja Puskesmas II Cilongok sebagian besar berisiko dilihat dari kebiasaan mereka seperti merokok, minum kopi, jarang berolahraga dan kebiasaan mengkonsumsi makanan instan. Masyarakat sebaiknya menjalani gaya hidup sehat dengan tidak merokok, menjauhi minuman keras, banyak minum air jernih, rutin berolahraga seperti jalan sehat, senam, bersepeda atau melakukan kerja bakti juga mengkonsumsi makanan dengan gizi seimbang yaitu 4 sehat 5 sempurna disertai banyak serat.

Intensitas suara di wilayah kerja Puskesmas II Cilongok sebagian besar memenuhi syarat kesehatan yaitu masih $\leq$ NAB . Sebagian kecil masyarakat dengan hasil pengukuran intensitas suara yang melebihi NAB dikarenakan kondisi rumah mereka yang berhadapan dengan jalan raya atau merupakan industri rumah tangga seperti produksi makanan seriping. Bagi masyarakat dengan intensitas suara > NAB khususnya yang merupakan industri rumah tangga bisa memposisikan ruang produksi terpisah dari rumah atau ruang keluarga, dan bagi pemukiman yang berhadapan langsung dengan jalan bisa menggunakan korden dimana terbuat dari bahan yang dapat meredam suara sehingga suara dari jalan tidak begitu mengganggu.

Hasil penelitian diketahui bahwa nilai $\mathrm{p}$ $=0,002$ lebih kecil dari 0,05. Maka dapat disimpulkan bahwa gaya hidup sehat mempengaruhi kejadian hipertensi di wilayah kerja Puskesmas II Cilongok Kabupaten Banyumas. Marliani (2007) menyatakan bahwa hipertensi atau tekanan darah tinggi merupakan gangguan pada sistem peredaran darah yang dapat menyebabkan kenaikan tekanan darah di atas nilai normal, yaitu melebihi 140 / 90 mmHg. Faktor-faktor yang dapat dimasukkan sebagai faktor risiko hipertensi adalah umur, jenis kelamin, etnis, hereditas, stress psikologis, pola makan, gaya hidup, obesitas, merokok, 
minum alkohol, pemakaian obat tertentu, intensitas suara, masa kerja dan sikap kerja.

Hasil uji chi square juga menunjukkan bahwa nilai $\mathrm{p}=0,118$ lebih besar dari 0,05. Maka dapat disimpulkan bahwa kejadian hipertensi di wilayah kerja Puskesmas II Cilongok Kabupaten Banyumas tidak dipengaruhi oleh intensitas suara. Pengaruh akibat terpapar intensitas suara keras lainnya adalah adanya rasa mual, lemas, stres, sakit kepala bahkan peningkatan tekanan darah (Pulat, 1992). Menurut Chanlett (1979), selain berdampak pada gangguan pendengaran, terdapat efek intensitas suara lainnya, yaitu : gangguan tidur dan istirahat, mempengaruhi kapasitas kerja pekerja. Gangguan intensitas suara bila dilihat dari segi fisik dapat berupa pupil yang membesar, dari segi psikologis intensitas suara dengan intensitas tinggi dapat menimbulkan stress, penyakit mental, dan perubahan sikap atau kebiasaan.

Hasil penelitian tentang hubungan antara gaya hidup sehat dan intensitas suara dengan kejadian hipertensi di wilayah kerja Puskesmas II Cilongok Kabupaten Banyumas menunjukkan bahwa gaya hidup sehat merupakan faktor yang paling mempengaruhi kejadian hipertensi. Analisis bivariat menunjukkan bahwa variabel gaya hidup berhubungan signifikan dengan kejadian hipertensi, demikian juga pada analisis multivariat tetap terjadi hubungan yang signifikan. Hal ini menunjukkan bahwa variabel independen tidak berinteraksi dengan variabel independen lainnya yaitu intensitas suara. Sebaliknya juga variabel intensitas suara pada analisis bivariat dan multivariat hubungannya tidak signifikan, maka semakin memperkuat bahwa variabel independen tidak saling berinteraksi.

\section{Kesimpulan}

a. Responden umur penderita penyakit hipertensi di Puskesmas II Cilongok Kabupaten Banyumas tertinggi terkena kasus adalah pada rentang umur 31-44 tahun yaitu terdapat 24 kasus (96\%). Jumlah penderita hipertensi di Puskesmas II Cilongok Kabupaten Banyumas persentase penderita dengan jenis kelamin perempuan (88\%) lebih banyak dari penderita berjenis kelamin laki - laki (12\%).

b. Gaya hidup sehat di wilayah kerja Puskesmas II Cilongok Kabupaten Banyumas sebagian besar berisiko sebanyak 26 orang (52,0\%).

c. Intensitas suara di wilayah kerja Puskesmas II Cilongok Kabupaten Banyumas sebagian besar sesuai NAB sebanyak 46 orang (92,0\%). d. Ada hubungan antara gaya hidup sehat dengan kejadian hipertensi di wilayah kerja Puskesmas II Cilongok Kabupaten Banyumas dengan nilai $\mathrm{p}=0,002$ lebih kecil dari 0,05.

e. Tidak ada hubungan antara intensitas suara dengan kejadian hipertensi di wilayah kerja Puskesmas II Cilongok Kabupaten Banyumas dengan nilai $\mathrm{p}=0,118$ lebih besar dari 0,05.

f. Faktor yang mempengaruhi kejadian hipertensi di wilayah kerja Puskesmas II Cilongok adalah gaya hidup dengan nilai Sig $=0,001<0.05$ dan merupakan faktor risiko terjadinya hipertensi dengan nilai $\operatorname{Exp}(B)=8,143>1$

\section{DAFTAR PUSTAKA}

Ahmadi,A.M.2005. Psikologi Penerbit Renika Cipta.

Perkembangan.

Andra.2007. Ancaman Serius Hipertensi di Indonesia. http://www.majalah-farmacia.com, diakses 26 Januari 2016.

Anggraini, A.D., danWaren, A. 2009. Faktor-faktor yang Berhubungan dengan Kejadian Hipertensi pada Pasien yang berobat di Poliklinik Dewasa Puskemas Bangkiang periode Januari sampai Juni 2008. Http://yayanakhyar.wordpress.com, diaksestan ggal 19 Januari 2016.

Arikunto,S.2006. Prosedur Penelitian: Suatu Pengantar Praktik. Jakarta: Rineka Cipta.

Babba, J., 2007. Hubungan Antara Intensitas Kebisingan di Lingkungan Kerjadengan Peningkatan Tekanan Darah (Penelitian pada Karyawan PT Semen Tonasa di Kabupaten Pangkep Sulawesi Selatan). Tesis, Program Pasca Sarjana Universitas Diponegoro, Semarang.

Baskoro,IS.2011.Hubungan Kondisi Fisik Rumah Dengan Kejadian Penyakit Tuberkolosis Di Wilayah Puskesmas I Sokaraja Kecamatan Sokaraja Kabupaten Banyumas Tahun 2010. Skripsi :Banyumas

Crea,M.2008. Hypertension. Jakarta: Medya.

DepartemenKesehatan RI.2009. Kendalikan Stress dan Hipertensi, Raih Produktivitas. http://www.depkes.co.id, diaksestanggal 12 Januari 2016.

Dinar,Hartanto.2011.Hubungan Kebisingan Dengan Tekanan Darah Pada Karyawan Unit 
Compressor PT Indo Acidatama Tbk. Kemiri Kebakkramat Karanganyar. http://core.ac.uk,diakses 2 Februari 2016

Eva,Hermawati. 2006. Perbedaan Tekanan Darah Tenaga Kerja Pada Intensitas Kebisingan Yang Berbeda Di PT Purinusa Eka Persada Semarang. http://lib.unnes.ac.id, diakses 2 Februari 2016

Irza,S.2009. Analisis Faktor Risiko Hipertensi Pada Masyarakat Nagari Bungo Tanjung Sumatera Barat. Medan: Universitas Sumatera Utara.

Indrawirawan, M. 2015. Tingkatan Hipertensi Menurut WHO. $\quad$ http://www.solusihipertensi.net, diakses 3 Februari 2016

KLH.1996. Keputusan Menteri Negara Lingkungan Hidup No.Kep- 48/MENLH/11/1996 tentang Baku Tingkat Kebisingan.Sekretariat Negara, Jakarta.

Marliani,L.2007. 100 Question \& Answers Hipertensi. Jakarta: PT. Elex Media Komputindo Gramedia.

Notoatmodjo, S. 2005. Metodologi Penelitian Kesehatan. Jakarta: RinekaCipta. 